\title{
SYSTEMS SENSITIVE DIALOGUE INTERVENTION
}

\author{
Sebastian Slotte \\ Systems Analysis Laboratory, Helsinki University of Technology, Espoo, Finland \\ P.O.Box 1100, FIN-02015 HUT, Finland \\ Email: sebastian@hut.fi \\ Tel. +358 503761967 \\ Fax +35894513096
}

Abstract

The paper presents a general methodology for dialogue interventions. Systems Sensitive Dialogue Interventions are viewed in the light of Gerald Midgley's general presentation of systemic intervention. By focusing on the dialogue philosophy of Martin Buber and the key elements in two popular dialogue methods it is proposed that a) enhancing individual participants' sensitivity to the unique human system they form is the primary task of a dialogue intervention, $b$ ) when designing dialogical interventions it is useful to use creatively elements from different available dialogical methods and c) dialogue interventions should be designed in experiential and existential rather than in metaphysical terms.

Keywords: dialogue, systemic intervention, methodology

INTRODUCTION 
Dialogue methods consist of specific rules and guidelines that aim to improve group interaction, collective learning and investigation. The central task of a dialogue is to provide a setting for communication and thinking in a group. Normally, the guidelines and rules for everyday debates, discussions and meetings are tacit. Of course, tacit rules vary from organization to organization and from culture to culture, and it is contingent upon which rules are applied. In dialogue interventions these rules and guidelines are made explicit.

Over the past ten years, dialogue has made a breakthrough in a number of fields. Dialogue has been recommended by organizational theoreticians and introduced in organizations for various purposes. The systems thinking variant of the learning organization (Senge, 1990; Senge et al., 1994), the knowledge creating company (Nonaka and Takeuchi, 1995), and the notion of corporate culture (Schein, 1999) are examples of general organizational theories which regard dialogue as a central organizational practice. Dialogue and dialogical methods are presented as a core practice of specific organizational areas such as team learning (Senge, 1990; Senge et al., 1994), leadership programs (Frydman et al., 2000), corporate responsibility and human rights (Frankental et al., 2000), and Business Ethics (Maclagan, 1998; van Hooft, 2001).

Moreover, dialogue has been implemented in participatory planning (Väntänen et. al., 2003) community building (Freire, 1972), and in national and international conflict resolution (Deutsch and Coleman, 2000; Susskind et al., 1999). Educational dialogue has been presented as an alternative to traditional teacher and fact centered education (Norris, 2003). Moreover, general recipes for dialogical interventions and consultancy have been put forth by both theoreticians and practitioners (Ellinor and Gerard, 1998; Flick, 1998; Isaacs, 1999; Simmons, 1999; Yankelovich, 1999).

The effort of this paper is to contribute to the development of a methodology for Dialogue Interventions called Systems Sensitive Dialogue Intervention. In accordance with Midgley's (2000) theory of systemic intervention, it is proposed that a methodology is an important aid for practitioners and researchers in designing proper and effective dialogue interventions. 
A proper dialogue intervention is defined as aiming at enhancing participants' sensitivity to the human system they form together. This sensitivity to the relational, inquiring, and synergetic dimensions is constitutive to dialogue. Moreover, an effective dialogue intervention produces change that is viewed as relevant e.g. improvement that is relevant from the viewpoint of the group engaged in dialogue.

The notion of Systems Sensitive Dialogue Intervention is a result of empirical experimentation with various dialogue methods and combinations. The interventions where carried out in various fields such as education (Hjelm and Slotte, 2001; Slotte, 2003; Slotte and Hjelm, 2002), decision making (Slotte and Hämäläinen, 2003), and natural resources conflict management (Väntänen et al., 2003). The research is related to a multidisciplinary research project on Systems Intelligence (Hämäläinen and Saarinen, 2004) of which dialogue is an integral part.

The paper is organized in the following way. Firstly, dialogue interventions are discussed in the light of Midgley's (2000) theory of Systemic Intervention. Secondly, reservations against the benefits of dialogue are discussed with references to Stacey (2001). Systems Sensitive Dialogue Interventions are presented as enhancing systems sensitivity in participants, resting on a creative use of methods and avoiding normative metaphysical demands.

\section{METHODOLOGY}

Recently, there have been some disputes about which methods create proper and efficient dialogue and are the most accurate (Kessels, 2001; Platts, 2002). The claim made here is that such discussions become obsolete if one takes the human system and its particular needs as a starting point for dialogue interventions. The primary task of the practitioner or facilitator is asking which actions and methods in any particular situation create proper dialogue e.g. an atmosphere of joint investigation, thinking together, inquiry, reflection and respect (Boele, 1997; Bohm, 1996; Buber, 1947) in a human system, such as a team, a class, a family, a group of stakeholders, a management team etc. The laws of social behavior and human systems are not as rigid as the laws 
of mechanism and nature and thus the same method is likely to produce different outcomes in different settings. Accordingly, we cannot expect that one method will produce proper dialogue in every situation. Rather, proper dialogue is reached through a creative use of different methods sensitive to the context.

According to Midgley (2000), a methodology for systemic intervention should take action for improvement as an explicit starting point. Improvement is defined temporarily and locally as different human systems and agents may use different boundary judgments (Midgley, 2000). In Systems Sensitive Dialogue Intervention, improvement is viewed through the realization of the desired consequences of the human system engaged in dialogue. The goals of the different dialogue methods include, for example, the clarification of a concept, conflict resolution and improved joint investigation. When a particular aim is realized it represents improvement, if the system engaged in dialogue judges so.

Thus, the methods to facilitate dialogue interventions should not be regarded as static but flexible and should be chosen in compliance with the expectations, needs, fears, values and maturity of the individuals participating, and with the human system they together create.

Finally, it is proposed that the facilitator of a dialogue intervention should be open about his normative vision (Midgley, 2000; Midgley and Ochoa-Arias, 1999) and not impose it upon others. Rather, in accordance with Midgley (2000) the participants engaged in a dialogue intervention should be encouraged to reflect on their ideological, metaphysical and pragmatic boundaries.

\section{CHALLENGES}

In recent criticism the impact of dialogue has been questioned. A powerful argument against dialogue as presented by and Bohm (1996) and Senge (1990) is made by Stacey (2001). Stacey makes a case based on learning and knowledge creation in organizations and argues that 
dialogue is an attempt to return to the ancient wisdom and conversational patterns of old cultures, such as those of North American Indians. Stacey rebukes this attempt as a nonsensical romantic idea of a lost Eden.

However, the references to Native Americans by Bohm should be regarded as a pedagogical way of illustrating alternatives to aggressive debate, advocacy and dialectics. The rise of the principles and the practice of dialogue is, in fact, a highly modern phenomenon with purely European roots (Taylor, 1989; Walker, 1999). Of course, dialogue was a central way to engage in theoretical matters with practical implications in the days of Socrates (Zanakis et al., 2003) and during the Hellenistic era of philosophy, the practice of dialogical skills, such as listening and presence became a central skill in the philosophical quest for a good life (Hadot, 1995). But not before the first half of the $20^{\text {th }}$ century did philosophers, such as Leonard Nelson, Martin Buber, and Mikhail Bakhtin formulate the basic ideas of dialogue as a practice that all men and women can and should engage in (Bradbury and Lichtenstein, 2000). It is these philosophies of dialogue that organizational practitioners, theoreticians, educationalists and consultants today, indirectly or directly, are building on in their real world interventions.

In opposition to Bohm's and Senge's dialogue conception, Stacey (2001) wants to draw attention to the multitude of everyday conversations that can be very creative but also very destructive. Moreover, Stacey claims that organizational theoreticians and consultants, instead of presenting dialogue and other conversational tools of an idealized kind, should focus on understanding the communicative interaction we currently engage in within hierarchical organizations. The answer to Stacey on this point is that there is extensive evidence suggesting that ordinary communication and the thinking that accompanies it often go wrong (Huczynski and Buchanan, 2001; Janis, 1982, Kahneman et al., 1982) in ways that may have negative, sometimes fatal, impact on a wide variety of organizational aspects resulting in failures of organizational change programs, failures of strategic programs, and the collapse of internal and external ethics (Dalla Costa, 1998; De Geus, 1997; Senge et al., 1999). It is widely 
accepted that ordinary communication and thinking can, and at times should, be the object of change (Huczynski and Buchanan, 2001). Far from being an idealization, dialogue takes into account ordinary ways of communication and can, in the form of dialogue sessions reflect on ordinary communication. The lessons and skills learned in dialogue session can also be transformed and incorporated into other more ordinary forms of communication and interaction (Slotte, 2004).

According to Stacey (2001), dialogue assumes a distinction between the individual and the collective mind. Stacey argues that the individual and the group are the same phenomenon and that there is no transcendent whole nor a group mind, nor a common pool of meaning outside of it. Rather, common meaning emerges in the communicative interaction between people in their local situation in the present (Stacey, 2001). However, contrary to what Stacey suggests dialogue is fundamentally not resting on such an ontological split, but rather in line with the view Stacey holds on this particular issue. Bohm whose ideas about dialogue the argument is directed against, clearly states (Bohm, 1992; Bohm,1996) that individual thinking is dependent on cultural structures of thought and that individual thinking has an impact on the common structure and content of thought in a given culture. In fact, dialogue rest on the idea that individual thoughts and collective thought are not separate but necessarily affect each other. Dialogue is rather in line with constructivism (Gergen et al., 2002). However, Stacey must be credited for his indirect criticism of the attempts to present dialogue as resting more or less on mysticism and as a strive for predetermined metaphysical insights. I will return to this point in the next to last section of the paper.

\section{SYSTEMS FOCUS}

Common for the different conceptions and methods of dialogue is the attempt to overcome individual and social barriers for sharing meaning, values and understanding. This attempt which is aided by a focus on listening, suspension of judgment, respecting, voicing and 
other rules of dialogue are effective means to protect groups from groupthink and situations were defensive and limiting interpersonal reasoning is strong (Huczynski and Buchanan, 2001).

Martin Buber's (1947) philosophy of dialogue paves the way towards seeing a group of dialoguers in the way I believe they should be viewed i.e. as a special kind of human system. Buber's views on dialogue have been applied in counseling and to some extent in conflict situations (Schuster, 1999) but when it comes to dialogue interventions in everyday human systems, such as organizations, Bubers views on dialogue and especially his view of relationality have not received the attention it deserves (Bradbury H and Lichtenstein B, 2000). For example, Dixon (1998), Flick (1998), Isaacs (1999), Senge (1990) and Yankelovich (1999) all mention Buber as an important figure without directly discussing Buber's view of applied dialogue (Buber, 1947). Though Buber did not propose an explicit dialogue method, he claimed that the necessary conditions for dialogue to emerge as a practice are the recognition of relationality, trust, the idea of communication with and responsibility (Buber, 1947).

According to Buber (1947) engagement in dialogue must be promoted by observing the relational character of all human systems. The importance of the relational aspects of dialogue cannot be emphasized enough. First and foremost dialogue becomes a way to relate with the other participants partaking in the dialogue. The challenge of the participants in dialogue is to recognize the uniqueness of the particular human systems they comprise. It is through the notion of this engagement that the dialogical skills such as listening, suspension, respecting and voicing (Isaacs, 1999) gain their meaning.

The entrance to dialogue is the realization that man is a relational creature that has the possibility to meet, communicate and create in a "space between". The relationality and the "space between" is not just something one might choose or wish to engage in. According to Buber (1947) it exists independently of any particular action between human beings. The "space between" is not observable in space and time in the same sense that a single individual and a collective are. It is 
something re-constituted in every accidental encounter between two persons (Buber, 1947).

Engagement in dialogue in Buberian terms is to fully engage oneself with the other.

Dialogue is not primarly a detached presentation of ones ideas and a detached inquiry into the ideas of others. Dialogue is not communication about but communication with (Buber, 1947). It is not plainly aimed at exchanging views between contributors. The focus of a dialogue intervention should primary be on the values, knowledge and ideas within the system currently engaged in dialogue, not on the values, knowledge and ideas of the individuals or the system they represent. To engage in dialogue does not necessarily mean giving up ones own point of view or fully accepting that of the other. Buber states that the individual sphere is untouched, but when people enter into dialogue the law of individual viewpoints no longer holds (Buber, 1947). Thus, for Buber the ontology of the dialogical, e.g. the reality and nature of dialogue is systemic in the systems thinking sense of the word: human systems in dialogue develop and create something new out of what the participating individual values, ideas and knowledge bring into them. In dialogue, participants as it were set aside the beliefs that thoughts or ideas can only be communicated from an individual to another and that forces external to these two individuals determine what is spoken. The space between can be characterized as a form of common reason where multiple voices create and work on single ideas.

The idea of the relational character of communication differs strongly from the so called conduit metaphor which is the dominant view of communication, for example, in the lion part of managerial textbooks (Axley, 1984; Bokeno, 2002). According to the conduit metaphor, successful communication is like a pipeline. Messages are understood as information that are transmitted from a sender to a receiver, decoded by the receiver, and successful if the meaning of the message is the same at both ends (Bokeno, 2002). According to Bokeno the conduit metaphor which describes how the understanding and practice of communication is perceived in organizations, is theoretically inappropriate, often dysfunctional and ineffective and a hindrance for 
implementing programs for creative, playful and innovative communication such as dialogue. If the conduit concept is dominating and not questioned when dialogical communication is introduced, dialogue interventions are in danger of loosing their rich, constructive and productive power (Bokeno, 2002).

An example of why a dialogue intervention might fail due to the mistake of viewing dialogue as conduit communication is found in the practice that is called cross-cultural dialogue (Du Bois and Hutson, 1997). Cross-cultural dialogue has recently been criticized for encouraging knowledge of other participants that is considered inappropriate (Jones, 1999). In a cross-cultural dialogue where white and black students were participating in order to exchange information about their own culture the demands by white students to know in effect marginalized the black students enforcing colonizing attitudes and strengthening prejudices. According to Jones (1999), emphatic knowing in cross-cultural dialogue can thus prevent us from recognizing our own systematic complicity.

From the viewpoint presented here, so called cross-cultural dialogue is not dialogical because its reliance upon the conduit metaphor prevents participants in dialogue to perceive each other as forming a unique human system. In a dialogue situation participants practice and focus on the virtues of dialogue, pay attention to their own habits of thought, mental models and possible prejudices. Especially dialogue that aims at mediating in conflicts between participants should aid understanding and respect for their counterparts by encouraging meeting the person behind the system or position they represent. Engagement in group dialogue leaves personal integrity intact but allows for surprise and unpredictable innovations in the interplay between dialoguers. According to Buber, a criterion for dialogue is that participants have the intention of establishing mutual relations (Buber, 1947).

Naturally, participants in a dialogue also have obligations and commitments to other systems and goals. The point emphasized here is that dialogue is especially well suited for 
understanding and working with the human system one is temporarily engaged with. When a dialogical relationship is established, it can well serve as a basis for discussing and reflecting on commitments to other human systems.

\section{MIXING METHODS}

The systems emphasis in Systems Sensitive Dialogue Intervention bears consequences on method. The proposal here is that the starting point of a dialogue intervention should not be one given method and its utilizations for a given purpose but rather the needs and challenges of the human system that is to be engaged in dialogue. The human system comes first, then method. This is not to say that methods are superfluous. However, the design and facilitation of dialogue is situational. Methods chosen should correspond to the motivation and maturity of the participants of dialogue.

In the following I shall briefly present two popular dialogue methods, Bohmian and Nelsonian dialogue in order to show that both, despite their differences, have strengths and can be used in dialogue interventions.

\section{The Bohmian Method}

According to the Bohmian School of dialogue, the focus in dialogue should be on process rather than on content. A dialogue should not have a predetermined agenda or a prefixed content (Isaacs, 1999; Senge, 1994; Simmons, 1999). By paying attention to the guidelines or virtues of dialogue, the agenda or issues are said to emerge during the dialogue process itself (Bohm, 1992; Bohm, 1996). Isaacs (1999) discusses four principal virtues of dialogue: listening, suspension of judgment, expressing and respecting. The virtues are not simply presented as virtues that one can automatically turn to but rather as skills that one should develop and learn to practice. Other important virtues or skills presented by Isaac (1999) and other theoreticians and practitioners include thinking together, encouraging others to speak, focusing on the issue and not on the 
personal character of other participants, winning together rather than winning for yourself, speaking from experience, and changing the viewpoint.

The reason to engage in dialogue is, for Bohm and others who share his views on dialogue, a practical matter. Dialogue creates shared meaning, values and a sense of community that supports joint action and the creation of culture (Bohm, 1992). By making dialogue one of the core principles of an organization or a community a new communication and thinking culture can emerge. Isaacs (1999) and Senge (1994) provide a lot of examples of this. For Senge et al. (1994) dialogue becomes a way to align action. According to Senge (1990), Bohmian type of dialogue gives access to such information and meaning that cannot be accessed individually, enhances new action, provides individuals with collective meaning and offers a place for innovation and inquiry. Furthermore, all these capabilities are thought to improve efficiency in groups and in organizations.

\section{The Socratic Method}

Leonard Nelson (1965) developed the Socratic Method. Today it is chiefly known as Socratic Dialogue or Neo-Socratic Dialogue. Socratic Dialogue is a way to engage people in an advanced philosophical dialogue. The method should naturally not be confused with the Socratic dialogues of Plato even if it is inspired by Socrates (Boele, 1997). Participation in a Socratic dialogue does not require prior experience in philosophy but an interest to discuss philosophical and ethical questions and a willingness to distance oneself from one's own commitments (Boele, 1997; Van Hooft, 2001). In organizational contexts, Socratic dialogue has become especially popular in developing and investigating values and business ethics (Bolten, 2001; Kessels, 2001; Van Hooft, 2001). In contrast to the idea that dialogue is rather process than content, Socratic dialogue stands out in its emphasis on a predetermined topic or question. The core of Socratic Dialogue is called "regressive abstraction". Regressive abstraction is an inquiry into the everyday experiences of participants and their understanding of these experiences by comparing, analyzing and seeing them in the light of the general concepts they are founded on. For example, a concrete experience 
conceptualized and described as an instance of freedom is contrasted with a general definition of freedom. Both the concrete experience and the abstraction are developed in the course of the dialogue by the dialoguers themselves.

A Socratic Dialogue continues with a question of investigation, for instance: "What is meaningful work?", "What is freedom?", or "What is love?". The dialogue starts with all participants giving a personal example of a situation were they feel that an instance of the matter of investigation was realized. The participants, when presenting their examples, do not have to prove that their examples are an instance of the matter being investigated. Intuition or feeling is enough. The example should be one in which the participant herself is a main character. Also, the example should be concrete in space and time. For example; "Two weeks ago on Sunday, when visiting a friend of mine the following happened". The dialogue proceeds by discussing which one of the examples should be chosen as a core example of the investigation. After choosing one example the dialogue gradually reaches an increasingly abstract level culminating in a core definition: E.g. "freedom is X" were X stands for a sentence of attributes suggested and dialogued about amongst the participants. Thereafter the dialogue proceeds back to the concrete by analyzing the abstract judgments principles and rules and ending at the question about its applicability in concrete life.

\section{Content and Process}

For a general methodology of dialogue in Systemic interventions, both the Bohmian and Nelsonian methods are important. Systems Sensitive Dialogue Intervention takes into consideration both content and process. Dialogue intervention can focus solely on content but often such dialogues do not have an impact on the way people interact. It does not provide dialoguers with a new ability for interaction e.g. systems sensitivity. The merits of Socratic Dialogue in a Systemic Intervention is that it provides a structured way to engage in dialogue and that dialoguers find perspectives on the issue from personal experience, thus avoiding speculation and possible power differences due to, for example, educational level or position. 
When the choice of method is based on the needs of the human system that is to be engaged in dialogue, a combination of methods can be useful. For instance, a conflict situation might require that participants improve their listening skills, are encouraged to show respect for other stakeholders, and learn to think together. However, to engage in a dialogue with no agenda can easily grow into a feeling that it is a waste time especially if it is a conflict situation and in times of pressing problems (Frydman et al., 2000; Slotte and Hämäläinen, 2003).

Systems Sensitive Dialogue Intervention emphasizes creative design of dialogue interventions. This has, for example been done in a natural resources decision making context (Slotte and Hämäläinen, 2003) where the reflection on boundaries as an improvement itself became important. The creative mix of dialogue methods can also be strengthened by other dialogue-related methods such as Appreciative Inquiry (Cooperrider and Whitney, 1999; Norum, 2001) and Communication Other/Wise (Bokeno, 2002).

\section{FROM METAPHYSICS TO EXPERIENCE}

Commitment to any particular metaphysics of dialogue is not a necessary precondition for engaging in dialogue. In a Systems Sensitive Dialogue Intervention, the facilitator refrains from advancing any metaphysical agenda of her own. Midgley (2000) points out and questions the fact that some people in the Community OR research community have included political agendas in their interventions. What applies to political agendas in Midgley's analysis applies to metaphysics in dialogue interventions. Bohmian dialogue, Socratic dialogue and Buber's presentation of dialogue include metaphysical claims such as "the implicate order" (Bohm, 1980)" the self-confidence of reason" (Boele, 1997) and "unity with God"(Buber, 1947). Ethically, practitioners and theoreticians have a full right to ascribe metaphysical characteristic to dialogue but these meta-level descriptions should not be imposed upon participants of a dialogue. When the applicative literature presents the metaphysical hypotheses and metaphors of the philosophies of dialogue as hard facts of dialogue, dialogue runs the risk of becoming a quest for these metaphysical and metaphorical states. There is the risk that the participants 
are submitted to a mystic procedure the ultimate goal of which is to experience a metaphysical state such as the implicate order, collective intelligence, the one, God or the Platonic world of ideas.

For example, if dialogue is defined as a quest for the platonic ideas or unity with God, it would be difficult and ethically questionable to engage a relativist or respectively an atheist in the dialogue. Participants in a dialogue should be given the sole right to draw their own metaphysical conclusions about the dialogue. Systems sensitivity does not involve, preclude or exclude any predetermined metaphysics but concerns observable relational aspects. In other words, it is proposed that the classification of the metaphysical nature of these experiences should be left to the dialoguers themselves. A Systems Sensitive Dialogue Intervention assumes that imposing any metaphysical ideas on dialoguers is at odds with the core ideas of dialogue. Participation in a dialogue which assumes some alien metaphysical principle can be awkward and restrain people from engaging in dialogue. When such metaphysical entities are presented as the goal of dialogue, the core philosophical principle of dialogue as a free encounter between participants becomes endangered. Ethically, there is a risk that the metaphysical entities are at odds with the personal worldviews of the dialoguers. Pragmatically, the methods to facilitate dialogue become guided by the metaphysical entities in favor of the needs, creativity and engagement of the dialoguers. Instead of creating a strong personal experience and a new attitude towards discussed issues it runs the risk of becoming a ritual predetermined by a metaphysical agenda.

It should be noted that dialoguers often express their personal experiences in subjective terms, sometimes reflecting personal, sometimes cultural values. When a group uses terms such as "magic" or "energy" to express their experiences, it should not automatically be viewed in metaphysical terms. Actors, as well as dialoguers, often use the world "energy" metaphorically or poetically to describe the level of co-operation. If understood literally the experience of "energy" and talk of energy levels could easily be dismissed as unscientific, but 
interpreted metaphorically as referring to positive emotions as described, for instance Collins (2004) it makes perfect sense.

However, practitioners should not hide their personal views on metaphysical questions if they are strongly committed to some. They should, however, make it clear that the participants are free to draw their own metaphysical conclusions.

\section{SUMMARY AND CONCLUSION}

This paper has sought to contribute to a methodology for dialogue interventions. Systems Sensitive Dialogue Intervention presents dialogue as one of many possible ways humans engage in communication. Systems Sensitive Dialogue Intervention recognizes the value of other language games in human systems and is not an effort to challenge these but is an aid in designing dialogical intervention in situations where such are perceived to be appropriate.

When participants learn to engage in dialogue, they learn a new way of relating that, in itself, is more of an act than mere speech or contemplation of ideas. This ability is can be used in any human encounter.

In a Systems Sensitive Dialogue Intervention the main focus of the participants is the human system that is comprised out of the participants. Of course, participants in dialogue bring with them their values, ideas and knowledge. However, a Systems Sensitive Dialogue Intervention strives not to compare, transmit or evaluate these. Instead, it focuses on what values, ideas and knowledge emerge from the dialogical relation.

Systems Sensitive Dialogue Intervention encourages scientists, philosophers, consultants and managers facilitating a dialogue to creatively combine content and process focused methods with the human system that is engaging in dialogue as the starting point.

The paper identifies the value of different dialogue-methods for dialogue interventions. The notion of Systems Sensitive Dialogue Interventions was developed as a result of 
empirical work with dialogue. It can be developed further by case studies of dialogical interventions that are designed in accordance with the recommendations presented here.

\section{Acknowledgements}

I would like to express my heartful thanks to Professor Esa Saarinen and Professor Raimo P. Hämäläinen of the Systems Analysis Laboratory of Helsinki University of Technology for valuable and encouraging comments and advice.

\section{REFERENCES}

Axley S. 1985. Managerial and organizational communication in terms of the conduit metaphor.

Academy of Management Review 24: 649-681.

Boele D. 1997. The benefits of a socratic dialogue or: Which results can we promise. Inquiry:

Critical Thinking Across the Disciplines 17(3): 48-70.

Bohm D. 1980. Wholeness and the Implicate Order. Routledge: London.

Bohm D. 1992. Thought as a System. Routledge: London. 
Bohm D. 1996. On Dialogue. Routledge: London.

Bokeno RM. 2002. Communicating other/wise. Reason in Practice -The Journal of Philosophy of Management 2(1): 11-23.

Bolten H. 2001. Managers develop moral accountability: The impact of Socratic dialogue. Reason in Practice, The Journal of Philosophy of Management 1(3): 21-33.

Bradbury H, Lichtenstein B. 2000.The space between: operationalizing relationality in organizational research. Organization Science 11: 551-564.

Buber M. 1947. Between Man and Man. Translated by Smith RG.Routledge and Kegan Paul: London.

Collins R. 2004. Interaction Ritual Chains. Princeton University Press: Princeton.

Cooperrider D, Whitney D. 1999. Appreciative Inquiry. Berret-Koeler Communications: San Francisco.

Dalla Costa J. 1998. The Ethical Imperative - Why Moral Leadership is Good Business. Harper Collins: New York.

De Geus A. 1997.The Living Company. Nicholas Brealey Publishing: London.

Deutsch M, Coleman PT. 2000. The Handbook of Conflict Resolution. Jossey-Bass: San Francisco.

Dixon N. 1998. Dialogue at Work. Lemos and Crane: London

Du Bois PM, Hutson JJ. 1997. Bridging the Racial Divide: A Report on Interracial Dialogue in America. Center for Living Democracy, Interracial Democracy Program: Brattleboro, VT.

Ellinor L, Gerard G. 1998. Dialogue. Wiley and Sons: New York.

Flick D. 1998. From Debate to Dialogue. Orchid Publications: Boulder. 
Frankental P, House F. 2000. Human Rights - Is It Any of Your Business. Amnesty International and The Prince of Wales Business Forum: London.

Freire P. 1972. Pedagogy of the Oppressed. Penguin: Harmondsworth.

Frydman B, Wilson I, Wyer J. 2000. The Power of Collaborative Leadership. ButterworthHeineman: Boston.

Gergen K, McNamee S, Barrett F. 2002. Realizing transformative dialogue. In The Transformative power of Dialogue Roberts N (ed). Elsevier: Oxford; 77-105.

Hadot P. 1995. Philosophy as a Way of Life. Blackwell Publishers: Oxford.

Hämäläinen RP, Saarinen E (eds.). 2004. Systems Intelligence: Discovering a Hidden Competence in Human Action and Organizational Life. Systems Analysis Laboratory Research Reports A88: Helsinki University of Technology.

Hjelm T, Slotte S. 2001. Dialogi hyvästä elämästä. Tammi: Helsinki.

Huczynski A, Buchanan D. 2001. Organizational Behaviour, 4th edition. Pearson Education Limited: Harlow.

Isaacs W. 1999. Dialogue and the Art of Thinking Together. Doubleday: New York.

Janis IL. 1982. Groupthink: Psychological studies of Policy Decisions and Fiascos. HoughtonMiffin: Boston.

Jones A. 1999. The limits of cross-cultural dialogue: Pedagogy, desire, and absolution in the classroom. Educational Theory 49(3): 299-317.

Kahneman D, Slovic P, Tversky A (eds). 1982. Judgement under Uncertainty: Heuristics and Biases Cambridge University Press: Cambridge. 
Kessels J. 2001. Socrates comes to market. Reason in Practice- The Journal of Philosophy of Management 1(1): 49-71.

Maclagan P. 1998. Management and Morality. Sage Publications: London.

Midgley G. 2000. Systemic Intervention. Kluwer: New York.

Midgley G, Ochoa-Arias, AE. 1999. Visions of community for community OR. Omega 27: 259274.

Nelson L. 1965 Socratic Method and Critical Philosophy: Selected Essays. Translated by Brown T.Dover: NewYork.

Nonaka I, Takeuchi H. 1995. The Knowledge Creating Company. Oxford University Press: New York.

Norris JA. 2003. From Telling to Teaching - A Dialogue Approach to Adult Learning. Learning by Dialogue: North Myrtle Beach.

Norum KE. 2001. Appreciative design. Systems Research and Behavioral Science 18(4): 323-333.

Platts J. (2002). Knowledge in action: A response to Jos Kessels. Reason in Practice-The Journal of Philosophy of Management 1(2): 83-84.

Schein E. 1999. Corporate Culture - a Survival Guide. Joessey Bass, San Francisco.

Schuster S. 1999. Philosophy Practice. Praeger Publishers: Westport, CT.

Senge P. 1990. The Fifth Discipline- The Art and Practice of the Learning Organization. Currency Doubleday: New York.

Senge P, Kleiner A, Roberts C, Ross R, Roth G, Smith B. 1999. The Dance of Change: The Challenge of Sustaining Momentum in Learning Organizations. Nicholas Brealey Publishing: NewYork. 
Senge P, Kleiner A, Roberts C, Ross R, Smith B. 1994. The Fifth Discipline Fieldbook: Strategies and Tools for Building a Learning Organization. Nicholas Brealey Publishing: NewYork.

Simmons A. 1999. A Safe Place for Dangerous Truths. AMACOM: New York.

Slotte S. 2003. Dialogue as systems Intelligence - What is systems intelligence? Abstract in English. In Systeemiäly!, Bäckström T, Brummer V, Kling T, Siitonen P (eds.) Systems Analysis Laboratory Research Reports B23. p 225.

Slotte S. 2004. Dialogue and systems intelligence: A work philosophy. In Systems Intelligence, Hämäläinen RP, Saarinen E (eds). Systems Analysis Laboratory Research Reports A 88. Helsinki University of Technology: 39-55.

Slotte S, Hämäläinen RP. 2003. Decision Structuring Dialogue. Systems Analysis Research Reports E13.Helsinki University of Technology.

Slotte S, Hjelm T. 2002. Dialogi hyvästä elämästä-opettajan opas. Tammi: Helsinki.

Stacey RD. 2001. Complex Responsive Processes in Organizations: Learning and Knowledge Creation. Routledge:London.

Susskin L, McKearnan S, Thomas-Larmer J. 1999. The Consensus Building Handbook: A Comprehensive Guide to Reach Agreement. Sage Publications: London.

Taylor C. 1989. Sources of the Self - The Making of Modern Identity. Cambridge University Press: Cambridge.

Van Hooft S. 2001. Overcoming principles: Dialogue in business ethics. Teaching Business Ethics 5(1): 89-106.

Väntänen A, Marttunen M, Turunen JP, Slotte S, Hiedanpää J. 2003. Vuorovaikkutteiset suunnittelumenetelmät Kemijärven Säännöstelyn Kehittämisessä. Suomen ympäristö 658. Finnish Environment Institute: Helsinki. 
Walker FN. 1999. Imprisonment and release through speech. In Outside The Wall: Reintegration strategies for the New Millenium. Proceedings of the Alberta Correctional Education Annual Conference:51-69.

Yankelovich D. 1999. The Magic of Dialogue - Transforming Conflict into Cooperation. Touchstone books: New York.

Zanakis SH, Theofanides S, Kontaratos AN, Tassios TP. 2003. Ancient greeks' practices and contributions in public and entrepreneurship decision Making. Interfaces 33: 72-88. 